\title{
High throughput non-invasive determination of foetal Rhesus D status using automated extraction of cell-free foetal DNA in maternal plasma and mass spectrometry
}

\author{
Simon Grill • Irina Banzola • Ying Li · Tea Rekhviashvili • Tobias J. Legler • \\ Sina P. Müller · Xiao Yan Zhong · Sinuhe Hahn · Wolfgang Holzgreve
}

Received: 14 July 2008 / Accepted: 14 August 2008 / Published online: 28 August 2008

(C) Springer-Verlag 2008

\begin{abstract}
Purpose To examine the potential high throughput capability and efficiency of an automated DNA extraction system in combination with mass spectrometry for the noninvasive determination of the foetal Rhesus D status.

Methods A total of 178 maternal plasma samples from $R H D$-negative pregnant women were examined, from which DNA was extracted using the automated Roche MagNA Pure ${ }^{\mathrm{TM}}$ system. Presence of the foetal RHD gene was detected by PCR for $R H D$ exon 7 and subsequent analysis using the Sequenom MassArray ${ }^{\mathrm{TM}}$ mass spectrometric system.

Results We determined that as little as $15 \mathrm{pg}$ of $R H D$-positive genomic DNA could be detected in a background of $585 \mathrm{pg}$ of $R H D$-negative genomic DNA. The analysis of the clinical samples yielded a sensitivity and specificity of 96.1 and $96.1 \%$, respectively.

Conclusion Our study indicated that automated DNA extraction in combination with mass spectrometry permits the determination of foetal Rhesus D genotype with an
\end{abstract}

S. Grill · I. Banzola · Y. Li · T. Rekhviashvili · X. Y. Zhong ·

S. Hahn $\cdot$ W. Holzgreve

Department Biomedicine, University Women's Hospital,

Basel, Switzerland

T. J. Legler · S. P. Müller

Department of Transfusion Medicine,

University of Göttingen, Göttingen, Germany

W. Holzgreve ( $\square)$

Laboratory for Prenatal Medicine and Gynaecological Oncology,

Women's Hospital, University of Basel, Hebelstrasse 20,

4031 Basel, Switzerland

e-mail: hahns@uhbs.ch; wolfgang.holzgreve@unibas.ch accuracy comparable to the current approaches using realtime PCR.

Keywords Rhesus D $\cdot R H D \cdot$ MALDI-TOF .

Non-invasive $\cdot$ Saber assay

\section{Introduction}

The non-invasive determination of the foetal $R H D$ status via the analysis of cell-free foetal DNA in maternal plasma or serum by real-time PCR is well established and already offered as a clinical service in a number of countries $[2,6]$. This development can greatly assist with the screening and monitoring of pregnancies at risk for haemolytic disease of the foetus and newborn (HDN), and also reduce the health care costs by avoiding unnecessary prophylactic treatment in those cases where the foetus is RHD negative [7].

It has recently been shown that MALDI-TOF (matrix assisted laser desorption ionization-time of flight) mass spectrometric devices, such as the Sequenom MassArray ${ }^{\mathrm{TM}}$ system, can be used for the detection of foetal genetic loci by the analysis of cell-free foetal DNA in maternal plasma or serum [11, 12]. The main advantage of this approach over conventional real-time PCR is that it permits the ready detection of foetal genetic loci which only differ slightly from the maternal counterpart, such as point mutations. Furthermore, it is possible to examine a large number of multiplex PCR products by mass spectrometry, implying that a large number of mutations or different loci can be examined in a single analysis [18]. A further attribute of the MassArray ${ }^{\mathrm{TM}}$ system is that it is highly amenable to high throughput analysis of several thousand samples per day. Consequently, it has been proposed that this system may be 
suitable for the analysis of cell-free foetal DNA in routine clinical diagnostic labs $[5,11,12]$.

As to date few large-scale studies have examined the suitability of such a system for this purpose, we have now performed a study in which 178 clinical samples were analysed in a blinded manner for the presence or absence of the foetal $R H D$ gene.

\section{Materials and methods}

Plasma sample collection and processing

The study was approved by the review boards from both the institutions. After written informed consent, $15 \mathrm{~mL}$ EDTA blood samples were obtained from pregnant women at risk for HDN caused by alloimmunization. The samples were processed on site at the University of Göttingen, Germany, by twofold centrifugation (1: $10 \mathrm{~min}, 2,700 \times g ; 2: 45 \mathrm{~min}$ $12,500 \times g)$. The plasma was divided into $1 \mathrm{~mL}$ aliquots and stored at $-80^{\circ} \mathrm{C}$. One aliquot of each sample was frozen and sent to Basel for analysis.

DNA isolation from maternal plasma

The automatic DNA isolation system MagNA Pure ${ }^{\mathrm{TM}}$ instrument (Roche Applied Science, Switzerland) was used for plasma DNA extraction. Following the "DNA LV Blood_1000.blk" protocol, DNA was extracted from $1 \mathrm{~mL}$ of $R H D$-negative maternal plasma with the Roche MagNA Pure $^{\mathrm{TM}}$ Pure LC DNA Isolation Kit-Large Volume. The DNA was eluted into $200 \mu \mathrm{L}$ of elution buffer and stored at $-20^{\circ} \mathrm{C}$ for later use. A sample volume of $50 \mu \mathrm{L}$ was available for analysis.

\section{Assay design}

The assay design was kindly provided by Sequenom Inc., USA. As only the foetal RHD gene is detected, and no corresponding maternal allele, a SABER (single allele base extension reaction) assay was used which exclusively detects the presence of the RHD 7 exon (see below). All oligonucleotides were synthesised and HPLC purified by Microsynth (Switzerland). Amplification primers contained a $5^{\prime}-10$ mer tag to keep them out of the analytical mass range.

PCR amplification

PCR reactions were performed in a total volume of $12.5 \mu \mathrm{L}$ containing $8 \mu \mathrm{L}$ of eluted cfDNA, $400 \mathrm{nM}$ of each primer (PCR-RHD7-fw and PCR-RHD7-rev, Table 1), $3 \mathrm{mM} \mathrm{Mg}^{2+}$, 0.5 U HotStart Taq DNA Polymerase (Qiagen, Switzerland), $50 \mu \mathrm{M}$ dNTPs and $1 \times$ PCR buffer. Thermal cycling was performed as follows: $15 \mathrm{~min}$ at $95^{\circ} \mathrm{C}$ followed by 50 cycles of $95^{\circ} \mathrm{C}$ for $45 \mathrm{~s}, 57^{\circ} \mathrm{C}$ for $45 \mathrm{~s}$ and $72^{\circ} \mathrm{C}$ for $1 \mathrm{~min}$. The reaction was completed with a final extension at $72^{\circ} \mathrm{C}$ for $7 \mathrm{~min}$.

Shrimp alkaline phosphatase (SAP) treatment

For the dephosphorylation of excess dNTPs, $4 \mu \mathrm{L}$ of a solution containing $3.06 \mu \mathrm{L} \quad \mathrm{ddH}_{2} \mathrm{O}, 0.34 \mu \mathrm{L}$ hME buffer (Sequenom Inc.) and $0.6 \mu \mathrm{L}$ shrimp alkaline phosphatase (Sequenom Inc.) were added to $12.5 \mu \mathrm{L}$ of PCR product. After incubation at $37^{\circ} \mathrm{C}$ for $60 \mathrm{~min}$, the enzyme was inactivated at $85^{\circ} \mathrm{C}$ for $5 \mathrm{~min}$.

Single allele base extension reaction

Four microliters of a solution containing $3.12 \mu \mathrm{L} \mathrm{ddH}_{2} \mathrm{O}$, $0.4 \mu \mathrm{L}$ Termination Mix C (containing 2', $3^{\prime}$-dideoxycytosintriphosphate (ddCTP), Sequenom Inc.), $0.4 \mu \mathrm{L} 25 \mu \mathrm{M}$ RHD7 extension primer (Table 1) and $0.08 \mu \mathrm{L}(2.56 \mathrm{U})$ Thermo Sequenase (Sequenom Inc.) were added to $18.5 \mu \mathrm{L}$ SAP treated PCR product. Thermal cycling was performed as follows: 2 min at $94^{\circ} \mathrm{C}$ followed by 99 cycles of $94^{\circ} \mathrm{C}$ for $5 \mathrm{~s}, 51^{\circ} \mathrm{C}$ for $5 \mathrm{~s}$ and $52^{\circ} \mathrm{C}$ for $5 \mathrm{~s}$.

Desalting and mass spectrometric analysis

A total of $29.5 \mu \mathrm{L} \mathrm{H} \mathrm{H}_{2} \mathrm{O}$ and $6 \mathrm{mg}$ of SpectroCLEAN resin (Sequenom Inc.) were added to $20.5 \mu \mathrm{L}$ extension product. The plate was rotated for $10 \mathrm{~min}$ at room temperature followed by centrifugation at $3,000 \times g$ for 3 min to pellet the resin.

A total of $15 \mathrm{~nL}$ of each desalted sample were dispensed onto a 384-format SpectroCHIP using a MassARRAY
Table 1 Oligonucleotides for PCR and extension reaction and corresponding masses used for the $R H D$ exon 7 mass spectrometry assay
PCR-RHD7-fw

PCR-RHD7-rev

RHD7 extension primer

SABER-assay terminator

Mass of extension primer

Mass of extension product

(Call: G)
5'-ACGTTGGATGGGGTGTTGTAACCGAGTGCTG-3'

5'-ACGTTGGATGCCGGCTCCGACGGTATC-3'

5'-ATTCCCCACAGCTCCAT-3'

$2^{\prime}, 3^{\prime}$-dideoxycytosintriphosphate (ddCTP)

$5050.3 \mathrm{Da}$

$5323.5 \mathrm{Da}$ 

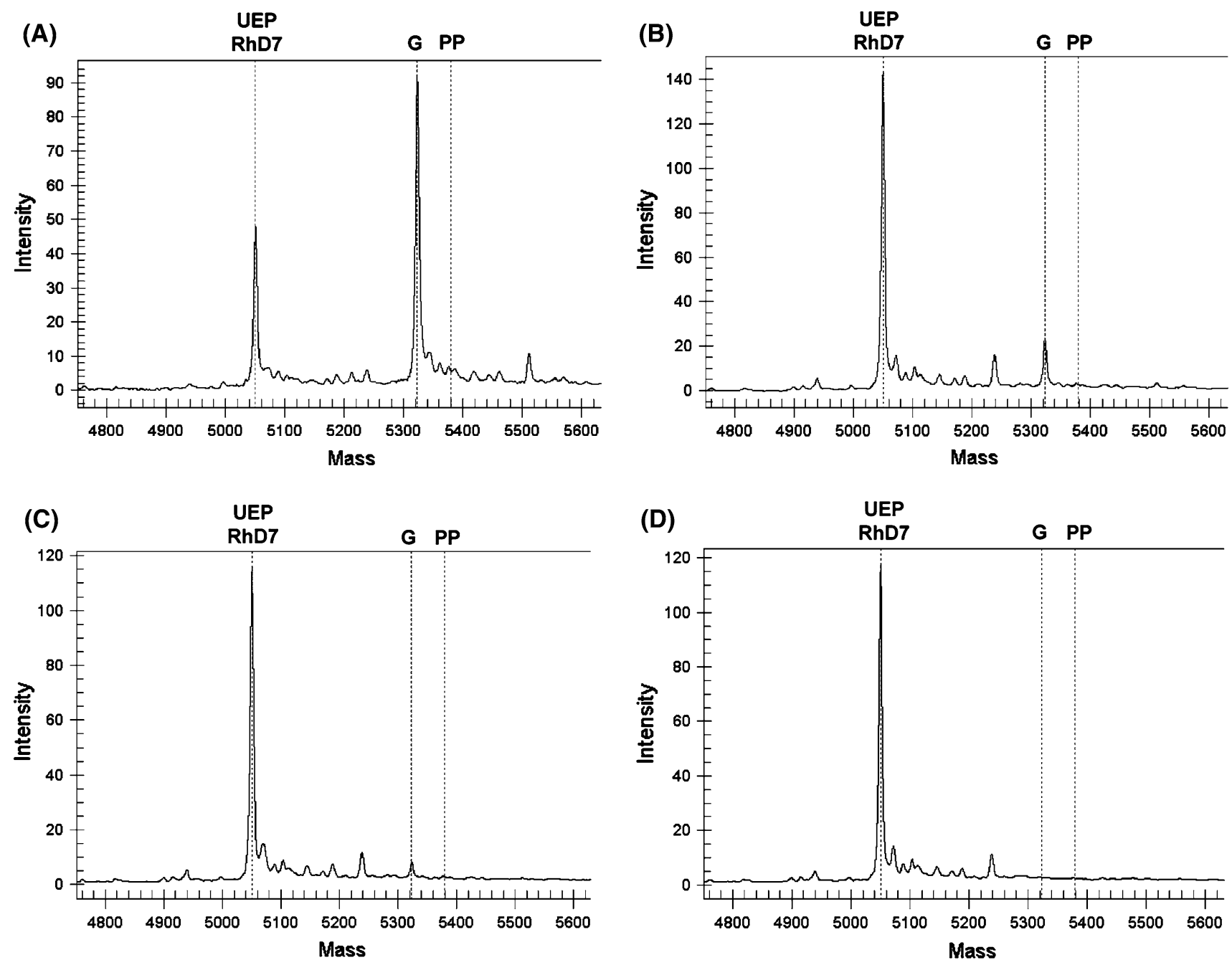

Fig. 1 Sensitivity and specificity of the RHD assay using the MALDITOF MS based SABER approach. RHD-positive genomic DNA was diluted into $R H D$-negative genomic DNA. The total DNA amount per reaction was $600 \mathrm{pg}$. a $600 \mathrm{pg} R H D$-positive genomic DNA. b $30 \mathrm{pg}$

nanodispenser (Sequenom Inc.) and subsequently analysed by MassARRAY Analyzer Compact. The data were recorded and interpreted by MassARRAY TYPER (Sequenom Inc.) software.

\section{Results}

Validation of the mass spectrometry Assay for RHD exon 7

$R H D$-positive DNA in $570 \mathrm{pg} R H D$-negative background. c $15 \mathrm{pg}$ $R H D$-positive DNA in $585 \mathrm{pg} R H D$-negative background. d $600 \mathrm{pg}$ $R H D$ negative genomic DNA. UEP unextended primer, $G R H D$ allele, $P P$ pausing peak

genomic DNA in a background of $585 \mathrm{pg}$ of $R H D$-negative genomic DNA (Fig. 1). This is almost equal to the three copies of the $R H D$ gene in a single reaction, indicating that the $R H D$ assay exhibits a degree of sensitivity and specificity suitable for the analysis of cell-free foetal DNA.

Detection of the foetal RHD exon 7 in maternal plasma

A total of 178 samples were analysed in a blinded manner. The results were confirmed by those obtained from serologTo evaluate the sensitivity of the SABER assay, we serially diluted $R H D$-positive genomic DNA into $R H D$-negative genomic DNA, such that the overall quantity of DNA was $600 \mathrm{pg}$ per reaction. This is the equivalent amount to that normally present in cell-free DNA preparations. Under these conditions, we were able to detect $15 \mathrm{pg}$ of $R H D$-positive ical analysis using cord blood in Göttingen. The presence or absence of the foetal $R H D$ exon 7 was determined following the analysis of the samples in duplicates. If the result was unambiguously positive or negative, the samples were scored accordingly. If the result was equivocal, the sample was re-analysed in duplicate. The sample was only 
Table 2 The results of foetal $R H D$ genotyping in maternal plasma using the MALDI-TOF based SABER assay

\begin{tabular}{lclll}
\hline Gestational age & $\begin{array}{l}\text { No. of } \\
\text { cases }\end{array}$ & $\begin{array}{l}\text { RHD } \\
\text { positive }\end{array}$ & $\begin{array}{l}\text { RHD } \\
\text { negative }\end{array}$ & $\begin{array}{l}\text { Sensitivity/ } \\
\text { specificity (\%) }\end{array}$ \\
\hline First trimester & 5 & $4 / 4$ & $1 / 1$ & $100 / 100$ \\
Second trimester & 127 & $91 / 93$ & $33 / 34$ & $97.8 / 97.1$ \\
Third trimester & 32 & $18 / 21$ & $10 / 11$ & $85.7 / 90.1$ \\
Unknown & 15 & $10 / 10$ & $5 / 5$ & $100 / 100$ \\
Total & 178 & $122 / 127$ & $49 / 51$ & $96.1 / 96.1$ \\
\hline
\end{tabular}

scored as $R H D$ positive if at least two positive signals were detected amongst the two sets of duplicates, else it was scored as $R H D$ negative.

Following a comparison of our results with those obtained by classical serology of the cord blood, we ascertained that out of 178 samples we had examined, five samples had been incorrectly scored as $R H D$ negative and two samples incorrectly determined as being $R H D$ positive (Table 2). This equates to a sensitivity of $96.1 \%$ and a specificity of $96.1 \%$. Our data show $96.1 \%$ concordance to those obtained by quantitative real-time PCR.

\section{Discussion}

Non-invasive prenatal $R H D$ analysis is currently most frequently performed using real-time PCR, either in conjunction with manual or automated procedures for the extraction of cell-free DNA from the maternal plasma/ serum samples $[4,9,13,15,16,19]$. In this study, we analysed the foetal $R H D$ status by mass spectrometry, in combination with automated system for the extraction of cell-free DNA from maternal plasma.

The validation of the assay showed that we were able to detect as little as $2.5 \%$ of $R H D$-positive genomic DNA in a background of $R H D$-negative genomic DNA, indicating that the assay is very sensitive. A similar sensitivity (20 pg mutant DNA in 580 pg wildtype DNA) has recently been reported by our group for the mass spectrometry based genotyping of the foetal KEL1 blood group from cell-free DNA in maternal plasma [11].

Out of 178 samples, five cases were incorrectly scored as $R H D$ negative and two were incorrectly scored as $R H D$ positive. Of those five false negative samples, three were obtained during the third trimester, while the remaining two were from the second trimester of pregnancy. The two samples that were scored false positive were from the second and third trimester or pregnancy. These remained to be assessed incorrectly, even after several rounds of re-analysis, indicating that the sample may have been contaminated. As the samples stem from a Caucasian population, a false positive result caused by the inactive allele $R H D \Psi[10,16]$ is unlikely, but can only be excluded convincingly by examining for the presence of this allele.

In those cases where the foetal $R H D$ gene cannot be detected, it is unclear, whether the foetus is Rhesus-negative or if the amount of foetal DNA in the sample is below the detection limit of the system. For the exclusion of the latter case, the detection of paternally inherited single nucleotide polymorphisms [12], the detection of a Y-chromosome specific sequence [8], or the detection of an epigenetic marker such as the foetal hypermethylated RASSF1A sequence [3] can be performed. In our current study, we were unable to perform such additional analyses due to very limited amount of sample available.

A recent review of large-scale studies reporting on the non-invasive determination of foetal $R H D$ status by the real-time PCR analysis of cell-free DNA indicated that accuracies between 95 and $99 \%$ could be attained [14]. As such, our data yielding an overall accuracy of $96.1 \%$ concur favourably with those obtained by real-time PCR.

In future studies we aim to make better use of the Sequenom MassArray ${ }^{\mathrm{TM}}$ mass spectrometric system, by performing multiplex analyses. In this manner it will be possible to detect variant $R H D$ alleles such as the $R H D \Psi$ gene [1, 17], as well as polymorphic markers indicating whether cellfree foetal DNA was present in the sample or not. This added information will increase the value of the analysis, and by being able to perform these numerous examinations in a single analytic run, help to reduce costs.

In this manner, the combination of an automated DNA extraction system and mass spectrometry may emerge as a competitive alternative to the current commonly used realtime PCR approaches used to determine non-invasively the foetal $R H D$ status.

Acknowledgments Funding from the European Commission for the Special Non-invasive Advances in Fetal and Neonatal Evaluation (SAFE) Network of Excellence (LSHB-CT-2004-503243) and the Swiss National Science Foundation (SNSF 3200B0-107697/1), from which this study was partially funded, is gratefully acknowledged.

\section{References}

1. Avent ND (2008) RHD genotyping from maternal plasma: guidelines and technical challenges. Methods Mol Biol 444:185-201. doi:10.1007/978-1-59745-066-9_14

2. Bianchi DW, Avent ND, Costa JM, van der Schoot CE (2005) Noninvasive prenatal diagnosis of fetal Rhesus D: ready for prime(r) time. Obstet Gynecol 106:841-844

3. Chan KC, Ding C, Gerovassili A, Yeung SW, Chiu RW, Leung TN et al (2006) Hypermethylated RASSF1A in maternal plasma: a universal fetal DNA marker that improves the reliability of noninvasive prenatal diagnosis. Clin Chem 52:2211-2218. doi:10.1373/clinchem.2006.074997

4. Costa JM, Giovangrandi Y, Ernault P, Lohmann L, Nataf V, El HN et al (2002) Fetal RHD genotyping in maternal serum during the 
first trimester of pregnancy. Br J Haematol 119:255-260. doi:10.1046/j.1365-2141.2002.03780.x

5. Ding C (2008) Maldi-TOF mass spectrometry for analyzing cellfree fetal DNA in maternal plasma. Methods Mol Biol 444:253267. doi:10.1007/978-1-59745-066-9_20

6. Finning K, Martin P, Daniels G (2004) A clinical service in the UK to predict fetal Rh (Rhesus) D blood group using free fetal DNA in maternal plasma. Ann N Y Acad Sci 1022:119-123. doi:10.1196/annals.1318.019

7. Finning K, Martin P, Summers J, Massey E, Poole G, Daniels G (2008) Effect of high throughput RHD typing of fetal DNA in maternal plasma on use of anti-RhD immunoglobulin in RhD negative pregnant women: prospective feasibility study. BMJ 336:816-818. doi:10.1136/bmj.39518.463206.25

8. Finning KM, Chitty LS (2008) Non-invasive fetal sex determination: impact on clinical practice. Semin Fetal Neonatal Med 13:69-75. doi:10.1016/j.siny.2007.12.007

9. Harper TC, Finning KM, Martin P, Moise KJ Jr (2004) Use of maternal plasma for noninvasive determination of fetal RhD status. Am J Obstet Gynecol 191:1730-1732. doi:10.1016/j.ajog. 2004.06.098

10. Legler TJ, Lynen R, Maas JH, Pindur G, Kulenkampff D, Suren A et al (2002) Prediction of fetal Rh D and Rh CcEe phenotype from maternal plasma with real-time polymerase chain reaction. Transfus Apher Sci 27:217-223. doi:10.1016/S1473-0502(02)00068-X

11. Li Y, Finning K, Daniels G, Hahn S, Zhong X, Holzgreve W (2008) Noninvasive genotyping fetal Kell blood group (KEL1) using cell-free fetal DNA in maternal plasma by MALDI-TOF mass spectrometry. Prenat Diagn 28:203-208. doi:10.1002/pd.1936

12. Li Y, Wenzel F, Holzgreve W, Hahn S (2006) Genotyping fetal paternally inherited SNPs by MALDI-TOF MS using cell-free fetal DNA in maternal plasma: influence of size fractionation. Electrophoresis 27:3889-3896. doi:10.1002/elps.200600084

13. Lo YM, Hjelm NM, Fidler C, Sargent IL, Murphy MF, Chamberlain PF et al (1998) Prenatal diagnosis of fetal RhD status by molecular analysis of maternal plasma. N Engl J Med 339:17341738. doi:10.1056/NEJM199812103392402

14. Maron JL, Bianchi DW (2007) Prenatal diagnosis using cell-free nucleic acids in maternal body fluids: a decade of progress. Am J Med Genet C Semin Med Genet 145:5-17. doi:10.1002/ajmg.c. 30115

15. Rouillac-Le SC, Puillandre P, Gillot R, Baulard C, Metral S, Le Van KC et al (2004) Large-scale pre-diagnosis study of fetal RHD genotyping by PCR on plasma DNA from RhD-negative pregnant women. Mol Diagn 8:23-31. doi:10.2165/00066982-20040801000004

16. van der Schoot CE, Hahn S, Chitty LS (2008) Non-invasive prenatal diagnosis and determination of fetal Rh status. Semin Fetal Neonatal Med 13:63-68. doi:10.1016/j.siny.2007.12.012

17. van der Schoot CE, Soussan AA, Koelewijn J, Bonsel G, Paget-Christiaens LG, de HM (2006) Non-invasive antenatal RHD typing. Transfus Clin Biol 13:53-57. doi:10.1016/j.tracli.2006. 02.021

18. Xiu-Cheng FA, Garritsen HS, Tarhouny SE, Morris M, Hahn S, Holzgreve W et al (2008) A rapid and accurate approach to identify single nucleotide polymorphisms of mitochondrial DNA using MALDI-TOF mass spectrometry. Clin Chem Lab Med 46:299305. doi:10.1515/CCLM.2008.071

19. Zhong XY, Holzgreve W, Hahn S (2001) Risk free simultaneous prenatal identification of fetal Rhesus D status and sex by multiplex real-time PCR using cell free fetal DNA in maternal plasma. Swiss Med Wkly 131:70-74 